\title{
Invitro Regeneration and Mass-Clonal Proliferation of Wheat through embryonic formation
}

\author{
Allah Jurio Khaskheli ${ }^{*}$, Muharam Ali ${ }^{1}$, Muhammad Ibrahim Khaskheli ${ }^{2}$, \\ Zohra Fatima Memon ${ }^{1}$, Sayyed Zakir Hussain Shah, Saleem Awan ${ }^{1}$, Bilqees \\ Magsi ${ }^{1}$, Ushba Jabeen Rajput ${ }^{1}$, Mohsin Ali Khaskheli
}

${ }^{1}$ Department of Biotechnology, Sindh Agriculture University, Tando Jam, Pakistan

${ }^{2}$ Department of Plant Protection, Sindh Agriculture University Tando Jam, Pakistan

*Address correspondence to aajkhaskheli@gmail.com

\begin{abstract}
The present study was conducted to determine the regeneration potential and producing mass-clonal production of wheat through embryogenesis. A total of 60 selected wheat seeds were surface sterilized and inoculated on different culture bottles under controlled condition. The seeds were emerged in MS basal media and later supplemented with different concentrations of BAP (Benzyl-amino purine) and IAA (Indole-acetic acid). The Observation on servile rate, regeneration capability, length ofleaves, length regenerated seedlings, length and number roots were observed. Resultsfurther expressed that the media MS-MIII showed maximum length of leaves and roots of seedlings followed by cultured on media supplemented with $10 \mu \mathrm{g} / \mathrm{L}$ or $20 \mu \mathrm{g} / \mathrm{L}$ or $30 \mu \mathrm{g} / \mathrm{L}$ each of IAA and BAP. Though, seedlings obtained under the concentration of $40 \mu \mathrm{g} / \mathrm{L}$ of IAA and BAP were relatively similar and showed significantly moderate result followed by cultured on the medium supplemented with $30 \mu \mathrm{g} / \mathrm{L}$. furthermore, the rooted plants were then transplanted into the substrate and acclimatized in the laboratory greenhouse where humid cavity available. The acclimatization in the humid cavity showed optimistic effect on the number of survived plants.
\end{abstract}

Keywords-Wheat, Tissue Culture, BAP, IAA, explants, Media.

\section{INTRODUCTION}

The regeneration and proliferation of whole plant from selected tissue is required for success application of Biotechnology in crop improvement. Wheat is one of the most important species of food crop. Therefore, it has been extensively investigated with respect toplant regeneration from In-vitroculture. Shoot regeneration is of crucial importance in the realization of the potential of cell and tissue culture techniques for plant improvement.
The process by which an embryo is formed and developed from the zygote is known as embryogenesis and when the egg cell is fused with a sperm cell is a prerequisite for this process. Additionally, in some plants such as Citrus and Mangifera may be formed by nuclear cells outside the sacs, such embryos are termed as adventives embryos, however no instance of ex-ovulo embryo development is known in the nature but it is growing in an artificial controlled media [1].Embryo present in the ovule, when the ovule mature it changes into seed. The foundation of agricultural industry is seed [2]. The ability to live of seeds is a critical factor for seed quality, which is closely related to germination percentage, resistance to abiotic and biotic stresses and plant performance, which decreases with an increasing storage period [3].

Wheat (TriticumaestivumL.) belongs to family gramineae/poaceae and it occupies $6^{\text {th }}$ place in the rank of most cultivated food crops, is growing all over the world and the most important cereal crop of Pakistan. Whilst, the production of wheat crop increased by the adoption of efficient cultural practices of crops such as use of best quality of seeds become necessary for cultivation of crop [4,5]. Although, tissue culture practices promising the production of high-quality types of seeds.There are many beneficial and useful wheat verities has been developed through controlled Invitro culture for drought tolerance [6], tolerant from salt [7], disease resistance [8], resistant from herbicide [9], Helminthosporiumsativum resistance [10], increase in the gliadin and glutenin subunits and protein content in the seed [11]. The invitro culture of wheat crop depends upon the wheat genotype [7], medium culture [13] and growth regulators [14]. The seeds of wheat when cultured on MS media supplemented with hormones had low frequency of formation of the callus but have a high regeneration capacity [7]. The use 
of seed's mature embryo decreases greenhouse costs, save time and space associated with growing plants to post anthesis for collection of immature embryo [15].

The purpose of this study wastoexamined the optimize concentration of MS medium supplemented with (BAP), (IAA) and to stabilize the method of regeneration of wheat on controlled laboratory condition. Though, new breeding method was described using in-vitro technique for growing plants from the seeds, get high yield of wheat crops in a tissue culture media by using the seeds of the wheat crops.

\section{MATERIALS AND METHODS}

\subsection{Explant source}

The dried seeds of wheat variety (Mehran) were purchased from the local market surrounding the area of Hyderabad district, Sindh Province, Pakistan. A total of 150 seeds were screened out with similar in size and structurally preserved.

\subsection{Soaking of seeds}

The samples of wheat seeds were soaked in distilled water and placed in an incubator at $20^{\circ} \mathrm{C}$. The samples were divided into five different treatment based on their soaking time. Out of 150 samples; each of 30 samples were soaked in the glass jars at $1 \mathrm{hr}, 6 \mathrm{hrs}, 12 \mathrm{hrs}, 18 \mathrm{hrs}$ and 24 hrs respectively, at constant temperature and pressure.

\subsection{Sterilization of seeds}

The sterilization of seeds was done by $5 \%$ of the common bleaching solution, the samples were shacked about 10 minutes under the laminar air flow cabinet in order to kill and remove the population of microbes, and dust particles from the seeds and creating aseptic environment for new born plantlets. After that seeds were rinsed 2-3 times with sterilized distilled water for removing the traces of bleaching solution.

\subsection{Media composition}

The composition of media was different in which MS medium, BAP, and IAA that were used at the different concentrations that are as follows:

$>\mathrm{MS}$ basalmedium $+10 \mu \mathrm{l} / \mathrm{L}$ BAP $+40 \mu \mathrm{l} / \mathrm{L}$ IAA

$>\mathrm{MS}$ basal medium $+20 \mu \mathrm{l} / \mathrm{L}$ BAP $+30 \mu \mathrm{l} / \mathrm{L}$ IAA

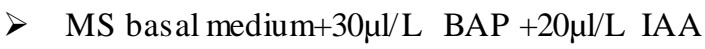

$>\mathrm{MS}$ basal medium $+40 \mu \mathrm{l} / \mathrm{L}$ BAP $+10 \mu \mathrm{l} / \mathrm{L}$ IAA

\subsection{Media preparation}

The preparation of media was done by adding MS basal medium $50 \mu \mathrm{l} / \mathrm{L}$, sterilized distilled water at constant concentrations supplemented with (BAP) benzyl-amino purine and (IAA) indole-acetic acid at different concentrations $10 \mu \mathrm{g} / \mathrm{L}, 20 \mu \mathrm{g} / \mathrm{L}, 30 \mu \mathrm{g} / \mathrm{L}$ and $40 \mu \mathrm{g} / \mathrm{L}$ as described in the above lines. We added sterilized cotton for supported the seedling during proliferations. Different concentrations of media showed different results for emerging the rooting and shooting of the wheat crop.

\subsection{Culturing of seeds}

The sterilized seeds were cultured in culturing bottles under the laminar air flow cabinet. Whereas, the common surgical sterilized cotton was used for supporting the germinated plantlets. About 50 $\mu$ l of MS media and $2 \mathrm{ml}$ of distilled water were used for growing the germinated plantlets. After that, cultured bottles were transferred to the incubator at constant temperature $20^{\circ} \mathrm{C}$ and pressure for $24 \mathrm{hrs}$. When germination was observed then two phyto-hormones (IAA) indole-acetic acid (Auxin) and (BAP) benzyl amino-purine (cytokinine) that were used in different concentrations $(10 \mu 1,20 \mu 1, \quad 30 \mu 1, \quad 40 \mu 1$ respectively) at different time duration $(1 \mathrm{hr}, 6 \mathrm{hrs}, 12 \mathrm{hrs}$, 18hrs, 24hrs)

\subsection{Maintenance of culture}

When the roots and shoots were observed, the plantlets were then shifted to the growth room. The temperature was maintained at $\pm 20^{\circ} \mathrm{C}$ in the growth room and also maintained aseptic environment for the new growing plantlets.

\subsection{Phenotypic observation}

The photographs were captured on daily routine basis. Phenotypic analyses was observed at two days intervals. Though the size and length of leaves were measure by using AlphaImager 2200 (Alpha Innotech).

\subsection{Statistics Analysis}

The obtained data were represented as the mean \pm SD with three biological replicates. Although, the data of different phenotype exploration were the mean \pm SD. Statistic 8.1software of analysis was used to identify differences between observations. Data were been categorized as shown $*$ and $* *$ point out in significant differences at $P<0.05$ and $P<0.01$ according to Student's $t$-test respectively.

\section{RESULTS}

\subsection{Invitro Regeneration of wheat plantlets through embryonic formation}

In the present study we have observed that he regeneration of wheat seedlings were obtained from the seeds in in-vitro conditions in the laboratory were disease resistance plants and were grown very well as compared to the invivo regeneration of plants in the field, because here we grown seedlings in aseptic conditions and proper constant temperature. As we know that wheat crop is Rabi season crop but we grew out of season this crop in the laboratory. When we grew these seeds by showing their regeneration capability they showed the outstanding results by adding MS medium for nutrient supplied, sterilized distilled water for imbibitions as well as enzymes activations purposed and finally added plant growth regulators or hormones such as auxins and cytokinines for proper growth and development of roots and shoots of seedlings of wheat crops. 


\subsection{Initiation and Proliferation of somatic embryos}

The beginning of embryos by the seeds embryogenesis process become auto-regulatory and maintained consecutive stages of the process without any or with minimal contributions from the external signals. The initiation and proliferation of somatic embryos dependedon the developmental stages of the plant material and factors of the growth medium (Figure 1). Though the initiation and proliferation of wheat seeds were observed that at $24 \mathrm{hrs}$ interval of soaking of seeds given surprising results as compared to others such as $18 \mathrm{hrs}, 12 \mathrm{hrs}$ and $6 \mathrm{hrs}$ intervals that showed medium results but $1 \mathrm{hr}$ interval of soaking of seeds showed minimum results of the seeds because soaking of seeds affected on imbibition as well as enzymes activation of the seeds of the wheat crops.

3.3 Proficiency of hormonal concentrations affects the regeneration potential of wheat

The regeneration potential of wheat on MS medium supplemented with different concentrations of IAA (Indole-Acetic Acid) and BAP (benzyl-amino purine) was observed. The results revealed that wheat seeds used as explants were cultured on MS medium without addition of these plant growth regulators showed significantly lower length of the leaves and roots of wheat seedlings compared to the explants grown on medium supplemented with various concentration of IAA and BAP. Results further expressed that the length of roots and leaves of seedlings cultured on media supplemented with $10 \mu \mathrm{g} / \mathrm{L}$ or $20 \mu \mathrm{g} / \mathrm{L}$ or $30 \mu \mathrm{g} / \mathrm{L}$ each of IAA and BAP concentration was relatively similar and were significantly moderate (Figure 2)followed by cultured on the medium supplemented with $40 \mu \mathrm{g} / \mathrm{L}$ of IAA and BAP revealed higher length of roots and leaves of the wheat seedlings.

\subsection{Numbers and height of leaves highly regulated by} cytokinines

It was observed that wheat seeds cultured on the medium supplemented with different concentrations of BAP (cytokinines). Results displayed that the numbers and height of leaves was remarkably higher on $40 \mu \mathrm{g} / \mathrm{L}$ of BAP concentration as compared to explants on other concentrations $10 \mu \mathrm{g} / \mathrm{L}, 20 \mu \mathrm{g} / \mathrm{L}$ and $30 \mu \mathrm{g} / \mathrm{L}$. it was further noted that any how the explants cultured on in-vitro cultured medium was not died the negligible growth of the leaves appeared up to the end of the experiment and showed lower rate of growth circumstances (Figure 3)

3.5 Roots of wheat exceptionally pretentious by AuxinCytokinin interactions

Roots of wheat seedlings per explants cultured on medium supplemented with different concentrations if IAA was observed (Figure 4-5). Results revealed that the length of the roots was remarkably higher on $40 \mu \mathrm{g} / \mathrm{L}$ of IAA concentration as compared to the explants on other concentrations $10 \mu \mathrm{g} / \mathrm{L}, 20 \mu \mathrm{g} / \mathrm{L}$ and $30 \mu \mathrm{g} / \mathrm{L}$. It was further noted that regardless the explants cultured on MS medium was not died, the growth of roots trivial appear up to the end of the experiment.

\section{DISCUSSION}

In these results clearly showed that theInvitro regeneration of the wheat crop through seeds is very important because it provides great yield as well as disease free plants. In nature, the somatic embryogenes is is a very common pathway during which embryonic and post-embryonic development of the plant have been formed[16, 17]. Invitro regeneration through somatic embryogenesis allows production of multiple genetically identical embryos may not require aridness as well as may skip the quiescence period prior to the germination and avoiding the wait for the following reproductive season. Somatic Embryo development includes key stages of zygotic embryogenesis the globular,scutellar and coleoptilar stages of monocotyledonous species [18,19]. The success in invitro culture is also very important by using plant growth hormones and proper optimization of their dosage in the plants of the wheat cultivars [20,21]. The beginning of somatic embryogenesis process becomes auto-regulatory and can maintain consecutive stages of the embryogenes is process without any or with minimal contributions from the external signals. Instead of how complicated the successive steps may seem the prototype foundation and persistence of this polarity from a homogenous group of cells[22]. The initiation of somatic embryogenesis depends on the developmental stages of the starting plant material and factors in the growth medium kenned by the complementary sensors in the cells maintenance of the embryogenic potential during successive cultivation requires the simultaneous activity of signalling and genetic processes $[\mathbf{2 3}, \mathbf{2 4}]$. The present process when we applied on theembryogenesis of wheat seeds at the different concentrations of (IAA), (BAP), MS basal medium and sterilized distilled water that gives good results. These results also demonstrated that invitro regeneration culture of the seeds of wheat crop enabled to get very high plant regeneration rates than other techniques such as callus culture that is the source of genomic alteration, albinism and sterility thus creating unwanted problems in tissue culture applications due to this reason we preferred this method.

\section{CONCLUSION}

The results concluded that seeds were emerged on MS basal media supplemented with different concentrations of BAP (Benzyl-amino purine) and IAA (Indole-acetic acid) showed remarkably better response for embryonic formation of wheat. Additionally, the rooted plants were been successfully transplanted into the substrate and 
acclimatized in the laboratory greenhouse; remarked that through tissue culture wheat seedlings get maximum survivals

\section{ACKNOWLEDGMENT}

We are very thankful to authority of department of Biotechnology, who has been authorized and facilitate us to perform the experiments.

\section{REFERENCES}

[1] Andrei S, Peter V, Bozhkov M (2014) Somatic embryogenesis: life and death processes during apicalbasal patterning. Journal of Botany, 65(5): 1343-1360.

[2] Huang M, Tang J, Yang B, Zhu Q (2016) Classification of maize seeds of different years based on hyper-spectral imaging and model updating. Computing ElectronAgriculture, 122: 139-145.

[3] Zhang T, Wei W, Zhao B, Wang R, Li M, Yang L, Wang J and Sun Q (2018) A Reliable Methodology for Determining Seed Viability by Using HyperspectralData from Two Sides of Wheat Seeds. Journal of Botany, 3(12) 223-226

[4] Ishfaq S, Syed DA, Shah AH, Khan RT, Bukhari SMF, Hameed I, Mubeen H, Awan N, Abbas SR and Raza S (2016) In-vitro optimization protocol of wheat cultivars in newly established lab of plant tis sue culture, Muzaffarabad, 3(3): 477-479.

[5] Carvalho TCD, Krzyzanowski FC, Ohlson ODC, Panobianco M (2012) Improved as sessment of wheat seeds.Vigour 2012, 36(6): 608-614

[6] Khah EM, Roberts EH, Elis RH (1989)Effects of seed ageing on growth and yield of spring wheat at different plant-population densities. Field Crops Research Bucks, 20: 175-190.

[7] Yasmin S, Khan IA, Khatri A, Seema N, Nizamani GS and Arain MA (2009)Invitro plant regeneration in bread wheat (Triticumaestivum 1.) Pakistan Journal of Botany, 41(6): 2869-2876.

[8] Zair IA, Chlyah, Sabounji K, Titahsen $M$ and Chlyah H (2003) Salt tolerance improvement in some wheat cultivars after application of In vitro selection pressure. Plant Cell Tis sue Organ Culture, 73: 237-244.

[9] Svabova $L$ and Lebeda A (2005)Invitro selection for improved plant TriticumaestivumL. Theory of Applied Genetics, 79: 609-617.

[10] 10. Saunders, Acquaah JWG, Renner KA and Doley WP (1992) Monogenic dominant sulfonylurea resistance in sugar-beet from somatic cell selection. Crop Science, 32: 1357-1360.

[11] Chawla HS and Wenzel G (1987)Invitro selection of barley and wheat for resistance against Helminthosporiumsativum. Theory of Applied Genetics, 74: 841-845.

[12] Yadav M, Singh KNK and Garg GK (2000) Development of lines of Indian wheat genotype for efficient regeneration using mature embryos. In:
Symposium on Biotech. for Sustain. Agri.G.B. Plant University of Ag \& Tech., Pantnagar, India. Pp.232

[13] Ye X, Xu H, Zhao L, Du L, Ye XG, Xu HJ, Zhao LL and Du LP (1998) Studies on improving wheat cultivars by tis sue culture. ActaAgronomicaSinica, 24: 310-314.

[14] Machii H, Mizuno T, Hirabayashi $\mathbf{H}$ and Hagio $\mathbf{T}$ (1998) Screening wheat genotypes for high callus induction and regeneration capability from anther and immature embryo cultures. Plant Cell Tissue Organ Culture, 53: 67-74.

[15] Cai R, Nakata K, Hirai Y and Cai R (1999) Plant regeneration from root callus of wheat (Triticumaestivum L.). Acta Agric. Shanghai, 15:1317.

[16] Hu WS, Li H, Hu SL, Li WX and Zeng HB (1998) The studies of immature embryo culture in vitro in wheat. The variation of gliadin and glutenin subunits and protein content in seed of progenies from regenerated plants. ActaAgronomicaSinica,24:204-212.

[17] Villareal RL, Mujeeb KA and Pena PJ (1999) Agronomic performance and quality characteristics of tissue culture derived lines of spring wheat (Triticumaestivum L.) cultivar Pavon. Cereal Res earch Commum, 27:41-48.

[18] Khalid M, Arshad M, GhulamMA and Razzaq A (2013) Tissue culture responses of some wheat (Triticumaestivum 1.) cultivars grown in pakistan Pakistan Journal of Botany, 45(1):545-549.

[19] Mahmood I, Razzaq A and Khan ZU (2012) Evaluation of tissue culture responses of promising wheat (Triticumawstivum L.) Cultivars and development of efficient regeneration sys tem. Pakistan Journal of Botany, 44(1):277-284.

[20] Sears RG and Deckard EL 1982)Tissue culture variability in wheat": callus induction and plant regeneration. Crop Science, 22:546-550.

[21] Mathias RJ and Simps on ES (1986)The interaction of genotype and culture medium on the tissue culture responses of wheat (Triticumaestivum L.) callus. Plant Cell, Tissue and Organ Culture, 7:1-37.

[22] Saad MR, Hamid T, Yasmin and Minhas NM (2004) Plant regeneration by somatic embryogenesis from callus of mature seed explants of bread wheat (T.aestivum L.). Pakistan Journal of Botany, 36:629634.

[23] Zale JM, Wier HB, Kidwell KK and Steber CM (2004) Callus induction and plant regeneration from mature embryos of a diverse set of wheat genotypes Plant Cell, Tissue and Organ Culture. Kluwer Academic Publishers. Printed in the Netherlands, 76:277-281

[24] Supria S, Zohorul I, Sadequl I, Mirza FH, Shahadat MH and Shahinul SMI (2017)Invitro sub culturing of wheat. Journal of Biologyand Life Sciences, 8(2):2157-6076. 


\section{Figures}
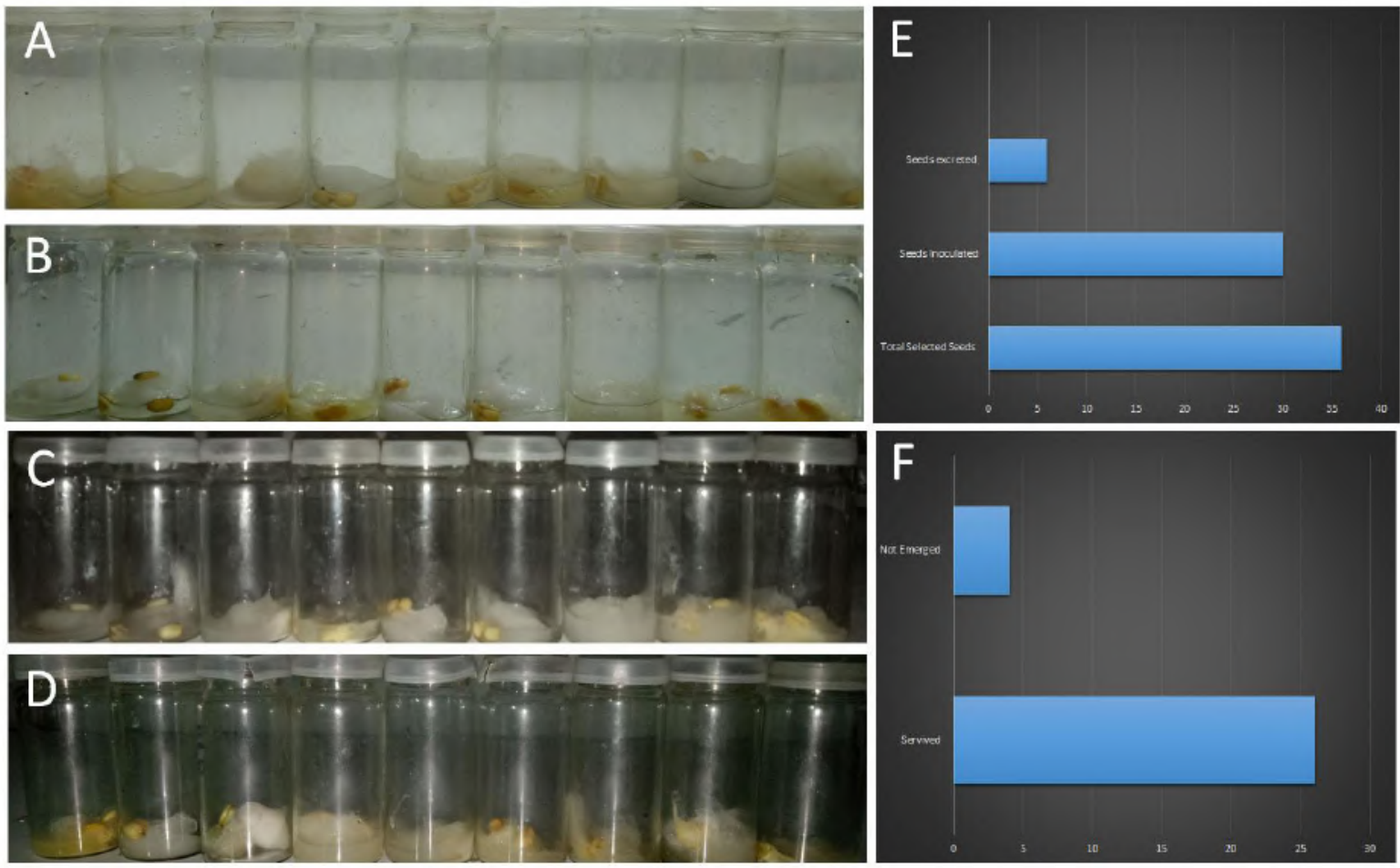

Fig.1: Invitro regeneration of Wheat through embryonic formation. (A) Seeds inoculated at MS basal medium $+10 \mu l / L$ BAP $+40 \mu \mathrm{l} / \mathrm{L}$ IAA. (B) Seeds inoculated at MS basal medium $+20 \mu \mathrm{l} / \mathrm{L}$ BAP $+30 \mu \mathrm{l} / \mathrm{L}$ IAA. (C) Seeds inoculated at MS basal medium $+30 \mu \mathrm{l} / \mathrm{L}$ BAP $+20 \mu \mathrm{l} / \mathrm{L}$ IAA. (D) Seeds inoculated at MS basal medium $+40 \mu \mathrm{l} / \mathrm{L}$ BAP $+10 \mu \mathrm{l} / \mathrm{L}$ IAA. (E) Percentile of seeds inoculations. $(F)$ Emergence of seed. The treatment means were compared using Least Significant Difference (LSD) at $5 \%$ level of Probability. Data are the average of three different biological replications.
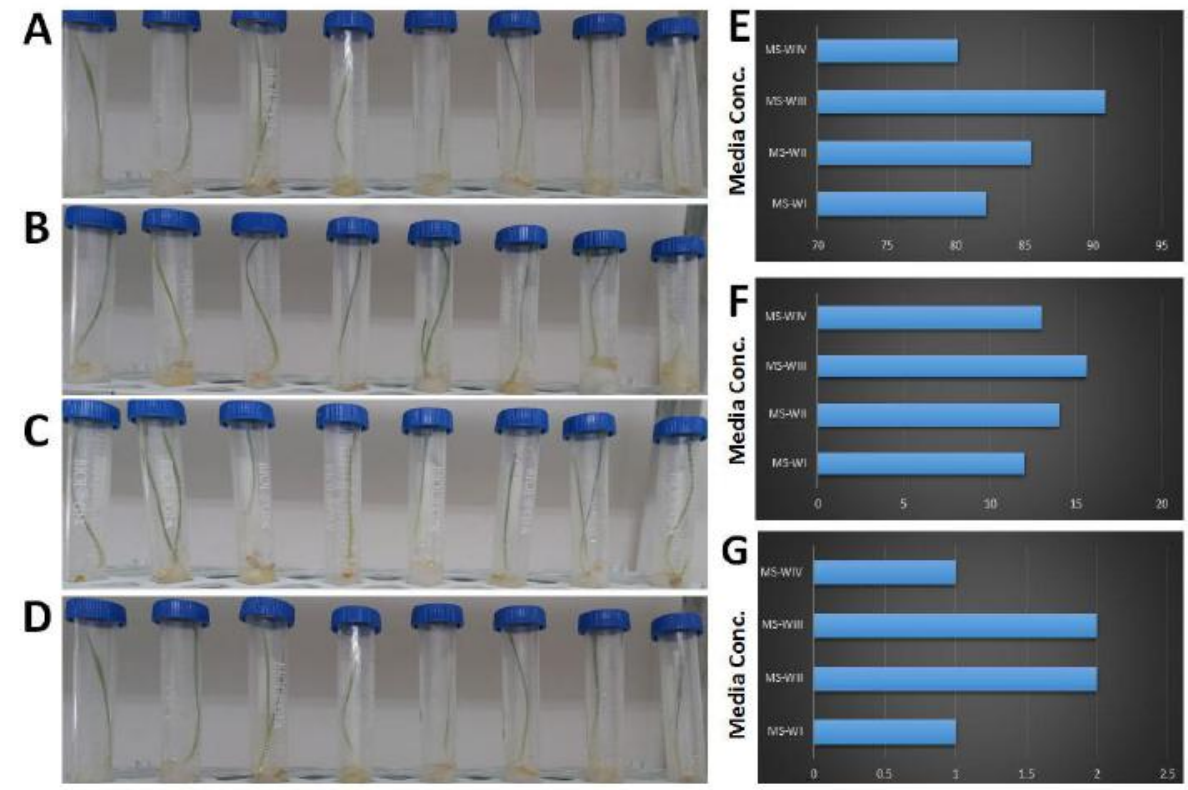

Fig.2: Proliferation of regenerated Wheat seedlings through embryonic formation. (A) Regenerated on MS basal medium $+10 \mu \mathrm{l} / \mathrm{L} B A P+40 \mu \mathrm{l} / \mathrm{L} I A A$. (B)Regenerated on MS basal medium $+20 \mu \mathrm{l} / \mathrm{L} B A P+30 \mu \mathrm{l} / \mathrm{LIAA}$. (C)Regenerated on MS basal medium $+30 \mu \mathrm{l} / \mathrm{L}$ BAP $+20 \mu \mathrm{l} / \mathrm{L}$ IAA. (D)Regenerated on MS basal medium $+40 \mu \mathrm{l} / \mathrm{L}$ BAP $+10 \mu \mathrm{l} / \mathrm{L}$ IAA. (E)Average of plants regenerated. $(F)$ Length regenerated leaves $(G)$ Encountering the number of leaves. The treatment means were compared using Least Significant Difference (LSD) at 5\% level of Probability. Data are the average of three different biological replications. 

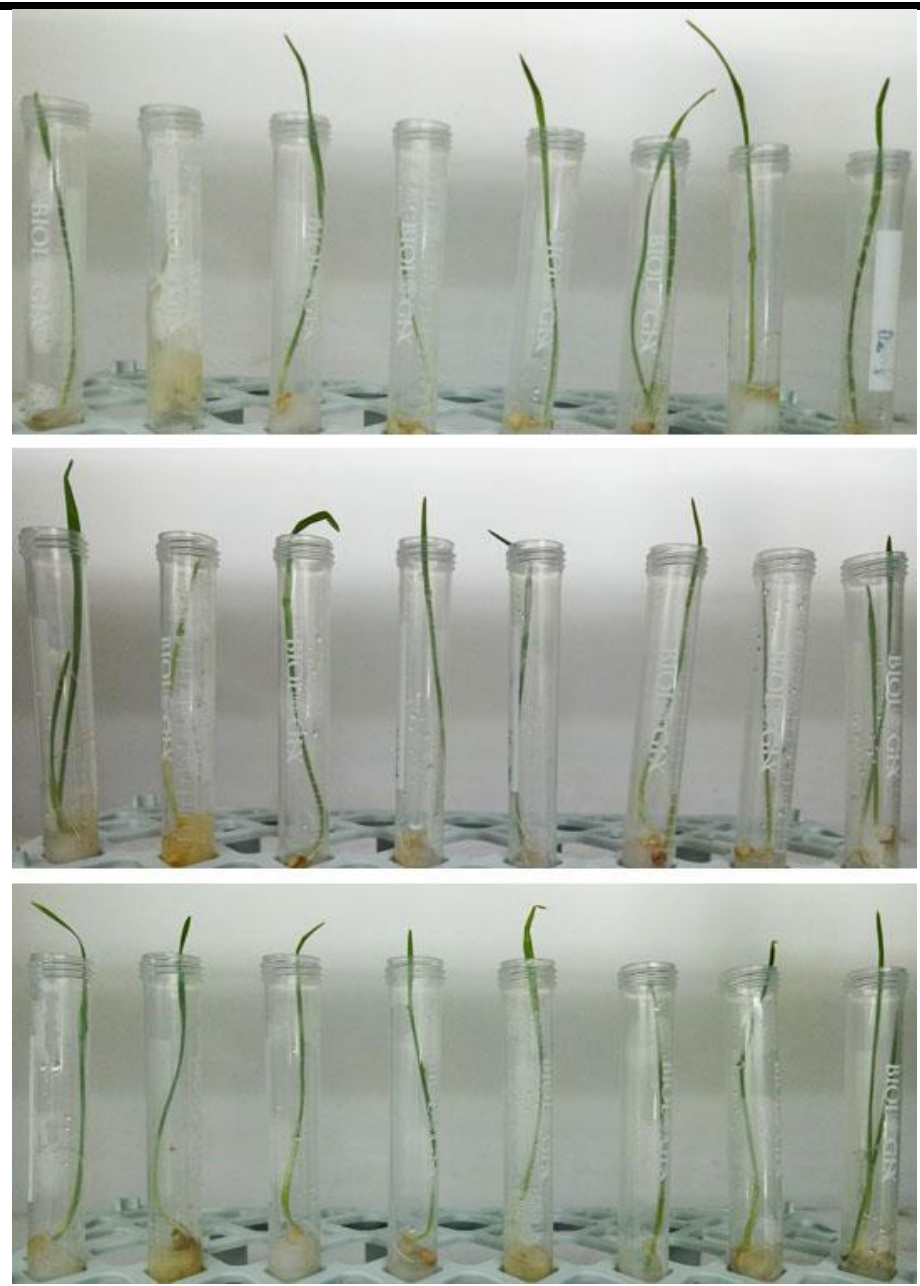

Fig.3: Proficiency of hormonal concentrations affects the regeneration potential of wheat. The treatment means were compared using Least Significant Difference (LSD) at $5 \%$ level of Probability. Data are the average of three different biological replications. 

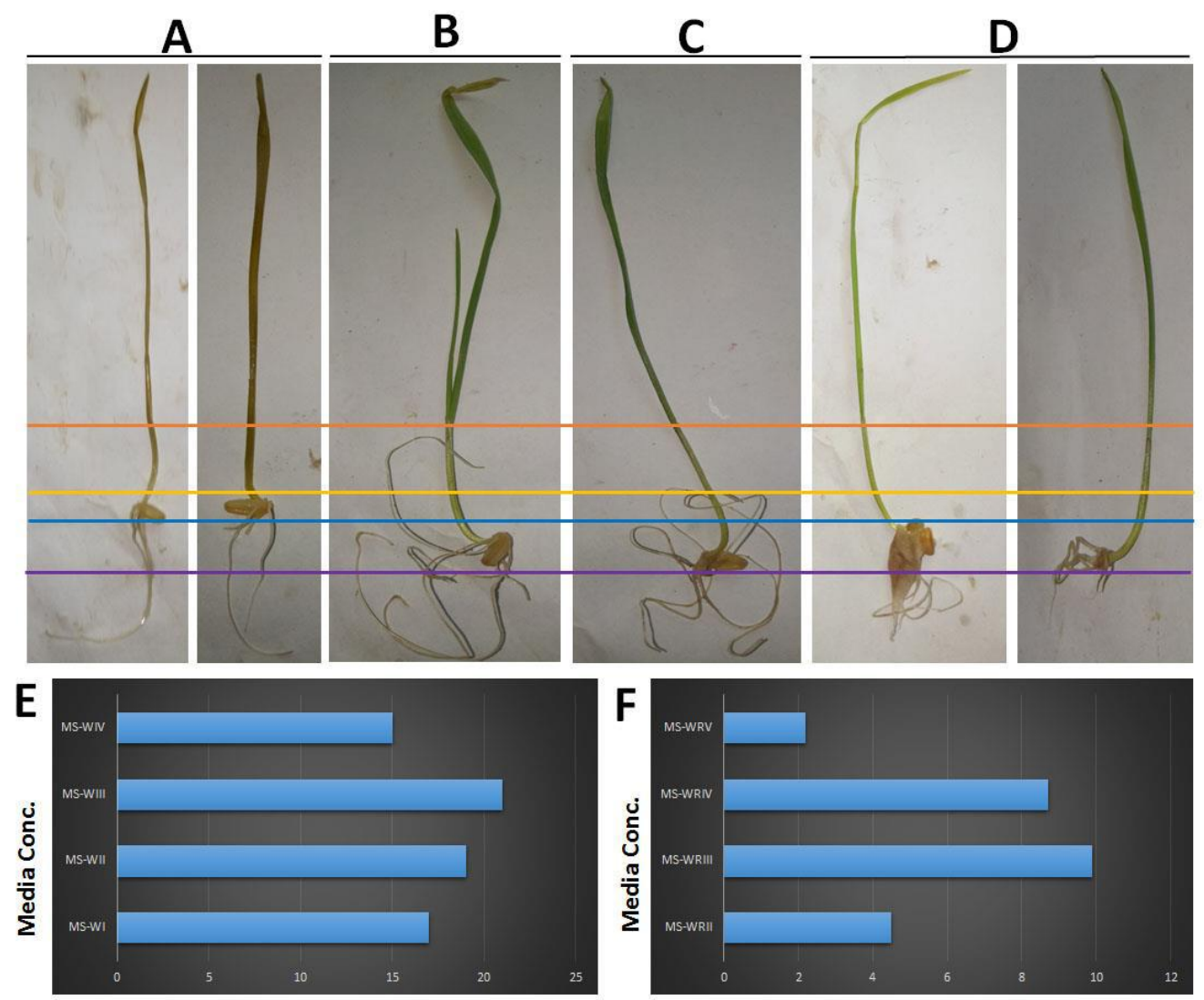

Fig.4: Roots of wheat exceptionally pretentious by Auxin-Cytokinin interactions. $(A, B, C, D)$ Invitro regenerated seedlings having pretentions roots. $(E)$ Length ofleaves $(F)$ Number of roots.The treatment means were compared using Least Significant Difference (LSD) at 5\% level of Probability. Data are the average of three different biological replications.
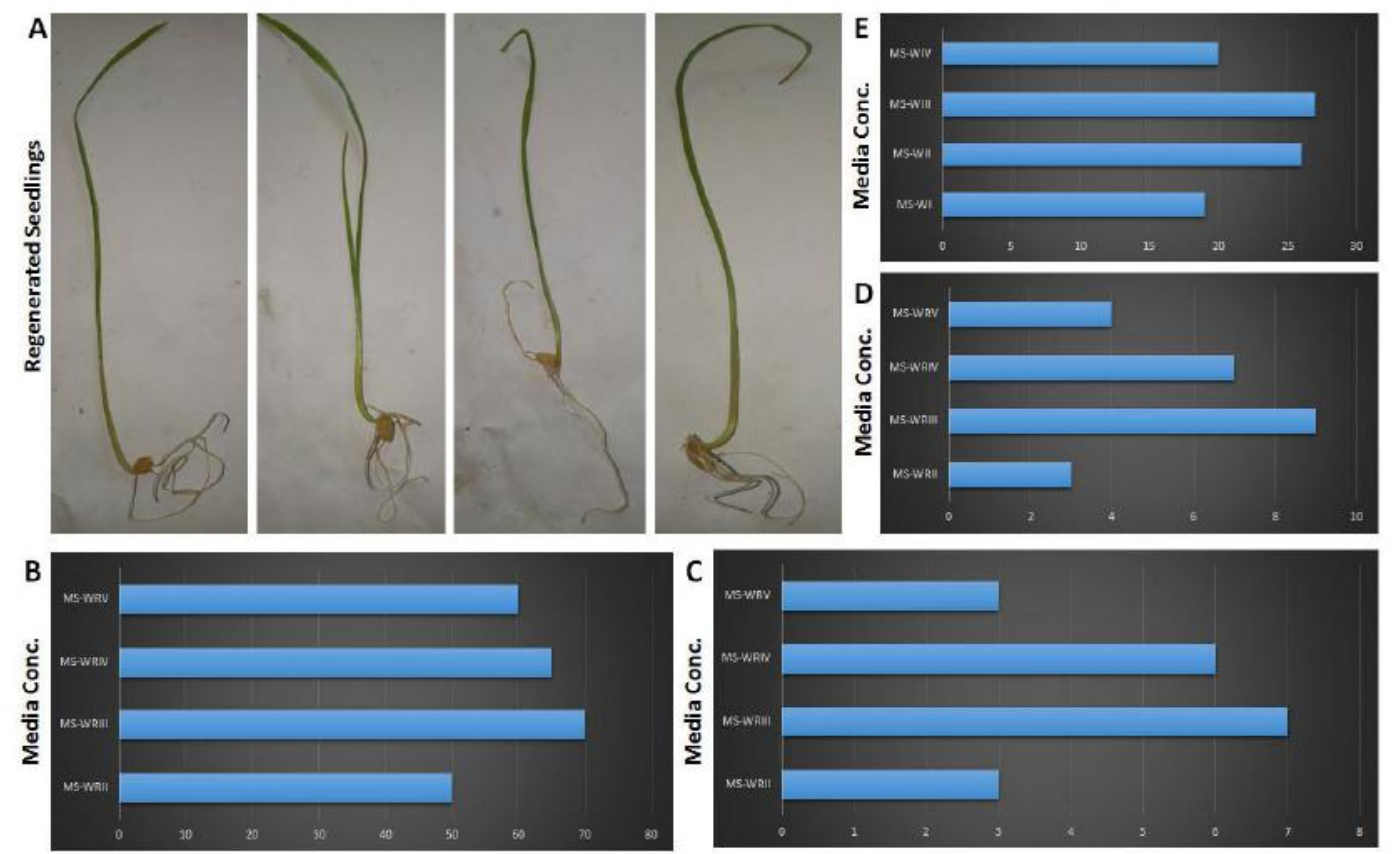

Fig.5: Mass-clonal production of wheat by embryonic formation. (A)Regeneratedseedlings at different hormonal concentrations. (B)Initiation rate of roots regeneration.( $C)$ Length ofroots. (D)Proliferated roots. (E) Average length of regenerated seedlings. The treatment means were compared using Least Significant Difference (LSD) at 5\% level of Probability. Data are the average of three different biological replications. 


\section{Supplementary Table}

Table.S-1 Composition of nutrient media used

\begin{tabular}{|c|c|c|c|c|}
\hline & Ingredients & Conc. & $\mathbf{m l}$ & g \\
\hline \multirow{19}{*}{ } & $\mathrm{NH}_{4} \mathrm{NO} 3$ (Ammonium nitrate) & \multirow{2}{*}{$50 X$} & \multirow{2}{*}{500} & 41.25 \\
\hline & $\mathrm{KNO}_{3}$ (Potas sium Nitrate) & & & 47.5 \\
\hline & $\mathrm{CaCl} 2.2 \mathrm{H} 2 \mathrm{O}$ (Calcium chloride) & $100 \mathrm{X}$ & 500 & 22 \\
\hline & $\mathrm{MgCl} 2.7 \mathrm{H} 2 \mathrm{O}$ (Magnesium sulphate) & \multirow{2}{*}{$100 \mathrm{X}$} & \multirow{2}{*}{500} & 18.5 \\
\hline & KH2PO4 (Potassium Phosphate) & & & 8.5 \\
\hline & Na2-EDTA (Sodium EDTA) & \multirow{2}{*}{$100 \mathrm{X}$} & \multirow{2}{*}{500} & 1.865 \\
\hline & FeSO4.7H2O (Iron Sulphate) & & & 1.39 \\
\hline & MnSO4.H2O (MangneseSulphate) & \multirow{7}{*}{$100 \mathrm{X}$} & \multirow{7}{*}{500} & 0.845 \\
\hline & ZnSO4.7H2O (Zinc sulphate) & & & 0.43 \\
\hline & H3BO3 (Boric Acid) & & & 0.31 \\
\hline & KI (Potassium iodide) & & & 0.0415 \\
\hline & $\begin{array}{l}\mathrm{Na} 2 \mathrm{MoO} 4.2 \mathrm{H} 2 \mathrm{O} \\
\text { (Sodium molybdate) }\end{array}$ & & & 0.0125 \\
\hline & CuSO4.5H2O (Copper sulphate) & & & 0.00125 \\
\hline & $\mathrm{CoCl} 2.6 \mathrm{H} 2 \mathrm{O}$ (Cobalt Chloride) & & & 0.00125 \\
\hline & Glycine & \multirow{5}{*}{$100 \mathrm{X}$} & \multirow{5}{*}{500} & 1 \\
\hline & Thiamine HCL (VB1) & & & 0.005 \\
\hline & Pyridoxine HCL (VB6) & & & 0.025 \\
\hline & Niacin (VB3) & & & 0.025 \\
\hline & Inositol/casein acid & & & 5 \\
\hline
\end{tabular}

Murashige and Skooge, 1962

Table.S-2 Composition of nutrient media for shoot induction

\begin{tabular}{cl}
\hline Media & \multicolumn{1}{c}{ Composition } \\
\hline MS-WI & MS basal medium $+10 \mu 1 / \mathrm{L} \mathrm{BAP} \mathrm{+} \mathrm{40 \mu 1/L} \mathrm{IAA}$ \\
MS-WII & MS basal medium $+20 \mu 1 / \mathrm{L} \mathrm{BAP}+30 \mu 1 / \mathrm{L}$ IAA \\
MS-WIV & MS basal medium $+30 \mu \mathrm{l} / \mathrm{L} \mathrm{BAP}+20 \mu 1 / \mathrm{L} \mathrm{IAA}$ \\
MS-WV & MS basal medium $+40 \mu \mathrm{l} / \mathrm{L} \mathrm{BAP}+10 \mu \mathrm{L}$ IAA \\
\hline
\end{tabular}

Table.S-3 Composition of nutrient media for root induction

\begin{tabular}{cc}
\hline Media & Composition \\
\hline MS-SI & MS basal medium $+10 \mu 1 / \mathrm{L} \mathrm{IAA}$ \\
MS-SII & MS basal medium $+20 \mu 1 / \mathrm{L} \mathrm{IAA}$ \\
MS-SIV & MS basal medium $+30 / \mathrm{L} \mathrm{IAA}$ \\
MS-SV & MS basal medium $+40 \mu \mathrm{l} / \mathrm{L} \mathrm{IAA}$ \\
\hline
\end{tabular}

